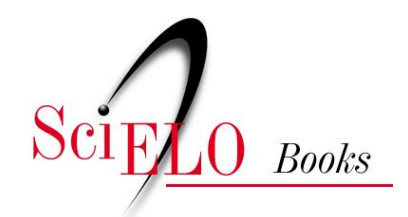

\title{
Cultura e desenvolvimento
}

uma visão crítica dos termos do debate

\author{
Lemuel Dourado Guerra \\ Jairo Bezerra da Silva
}

\section{SciELO Books / SciELO Livros / SciELO Libros}

GUERRA, LD., and SILVA, JB. Cultura e desenvolvimento: uma visão crítica dos termos do debate. In BRASILEIRO, MDS., MEDINA, JCC., and CORIOLANO, LN., orgs. Turismo, cultura e desenvolvimento [online]. Campina Grande: EDUEPB, 2012. pp. 195-233. ISBN 978-85-7879-194-0. Available from SciELO Books <http://books.scielo.org $>$.

\section{(2)(1)(2)}

All the contents of this work, except where otherwise noted, is licensed under a Creative Commons Attribution-Non Commercial-ShareAlike 3.0 Unported.

Todo o conteúdo deste trabalho, exceto quando houver ressalva, é publicado sob a licença Creative Commons Atribuição Uso Não Comercial - Partilha nos Mesmos Termos 3.0 Não adaptada.

Todo el contenido de esta obra, excepto donde se indique lo contrario, está bajo licencia de la licencia Creative Commons Reconocimento-NoComercial-CompartirIgual 3.0 Unported. 


\title{
Cultura e desenvolvimento: uma visão crítica dos termos do debate
}

\author{
Lemuel Dourado Guerra \\ Jairo Bezerra da Silva
}

\section{Introdução}

Sem pretender oferecer discussões exaustivas sobre os termos, o foco deste capítulo é colocar em discussão alguns pontos constitutivos do debate construído em torno da relação entre cultura e desenvolvimento. Nosso interesse maior é apresentar algumas ideias contra a corrente, referentes às maneiras pelas quais se tem falado sobre esses dois termos colocados em relação de certo modo intercausal. Assim, a partir de uma discussão sobre as condições em que emerge o papel da cultura nos processos de produção/indução/obstrução do que tem sido chamado de desenvolvimento, bem como sobre as maneiras pelas quais a implementação de estratégias, modelos e políticas de desenvolvimento levam em consideração a 
variável cultura e seus efeitos sobre as coletividades por elas definidas como alvo, apresentamos uma breve análise de um exemplo de discurso consagrado sobre a relação aqui focalizada e uma sugestão de pontos para uma agenda de pesquisa à qual os interessados no tema são convidados a questionar e contribuir.

O debate sobre a relação entre cultura e desenvolvimento é extremamente elusivo e ambíguo na medida em que os dois termos da relação são polissêmicos e sua conceituação é objeto de disputas mais ou menos explícitas. Em referência à cultura, há uma hesitação ligada a duas maneiras gerais recorrentes de defini-la: uma, que chamaremos de ampla ou antropológica - segundo a qual a cultura é vista como um conjunto de elementos que constituem o modo de vida de um povo, de uma comunidade; a outra, que chamaremos de especifica que define a cultura enquanto as diversas atividades ligadas às artes em todas as suas expressões. Esses dois caminhos conceituais implicam em abordagens diferenciadas, que tentaremos focalizar, ainda que brevemente, neste capítulo.

Outra maneira de esquematizar as linhas em torno das quais a retórica sobre a referida relação se organiza é aludir ao enfrentamento entre o que tem sido chamado de perspectiva hipermodernista (Cf. RAO; WALTON, 2004, p.10-11) e a corrente da critica cultural ao desenvolvimento.

A primeira delas, que pode ser encontrada, por exemplo, nos trabalhos de Harrison (2000), Huntington (2000) e Landes (2000), e, em certa medida, nos discursos que fundamentam a implementação de políticas de formação para o empreendedorismo e para a inovação, seria caracterizada pela visão de que sociedades nas quais predominam culturas 
tradicionais teriam dificuldade em se integrar ao desenvolvimento em sua lógica orientada pelo mercado, apresentando, portanto, um lento e penoso processo de crescimento. $\mathrm{O}$ desafio a ser enfrentado seria, de acordo com essa linha de pensamento, modificar a cultura das regióes, países, comunidades marcadas pela tradição, principalmente através da educação e dos vários tipos de mídia, no sentido de inculcar nos indivíduos um conjunto de valores favoráveis à mobilidade, ao investimento no novo, ao empreendedorismo.

A segunda perspectiva, a da crítica cultural ao desenvolvimento $^{1}$, tem como marca central uma visão questionadora dos discursos desenvolvimentistas euro-norte-americano cêntricos, articulados sob a orquestração, sobretudo, de economistas e de instituiçóes multilaterais tais como o Fundo Monetário Internacional e o Banco Mundial. Nesses discursos, seria operacionalizada uma definição de cultura como sistema de controle que estabelece classificações, hierarquizações entre países, economias, regióes ambiguamente definidas como do Norte e do Sul, o que teria como consequências centrais a criação e extensão das desigualdades entre países ricos e pobres (e dentro deles, entre as regióes mais e menos modernizadas, ocidentalizadas), as quais resultaram em taxonomias tais como as indicativas de graus de desenvolvimento - desenvolvido, subdesenvolvido, em desenvolvimento-, e num vocabulário que inclui expressões do tipo Terceiro Mundo e paises emergentes.

1 Exemplos dessa linha interpretativa podem ser encontrados em Escobar (1995, 2002), Hall (1992), Ferguson (1994, 2002). 
Para Ortiz (2008), o mais interessante na avaliação da relação entre cultura e desenvolvimento não seria o posicionamento favorável ou contrário à linha de causalidade entre as variáveis que cada um dos termos indica. Mais importante seria pensar o hiato entre elas, o qual seria determinado pela diferença ontológica entre os dois fenômenos colocados em relação.

Definindo cultura de modo amplo e enquanto um elemento constitutivo ontológico das sociedades, regióes, coletividades que as produzem e que nelas são produzidas, esse autor a considera algo que estaria fora da esfera da racionalidade instrumental. Somente em termos da definição de politicas culturais, referidas àquela maneira específica de falar sobre cultura, relativa a modelos de organização da produção, circulação e consumo das obras de arte em geral; de classificação, conservação e transmissão intergeracional do patrimônio definido pelos especialistas enquanto patrimônios artísticoculturais, é que a cultura poderia ser tocada enquanto algo a ser planejado, organizado, implementado.

Por outro lado, as diversas noções de desenvolvimento em suas vinculações com variáveis tais como crescimento econômico, industrialização, avanço tecnológico, progresso da ciência, democracia, sustentabilidade ambiental, aperfeiçoamento ético e outras dessa natureza, seriam uma invenção da(s) modernidade $(s)^{2}$, e pertenceriam ao domínio da racionali-

2 O plural aqui adotado se refere à variedade dos processos e modelos de modernização historicamente constituídos, os quais têm uma matriz inicial inequivocamente eurocêntrica, mas que guardam variações históricocontextuais específicas. Penso aqui, com Ortiz (idem), por exemplo, nos processos de modernização observados no Japão e nos Estados Unidos, ou no Sudeste e Nordeste do Brasil. 
dade, no qual seria perfeitamente possível planejar, atuar, implementar, organizar de várias maneiras, a depender das concepções teóricas e posicionamentos políticos partilhados (Cf. ORTIZ, 2008).

Vista essa distinção entre o status ontológico dessas duas categorias postas em relação mais especificamente a partir de meados do século XX, sendo a cultura, em sua definição ampla, uma variável cujo surgimento se confunde com a própria formação da espécie humana no planeta, e sendo, em sua definição estrita, junto com o desenvolvimento, invenções ligadas à modernidade euro-estadunidense cêntrica, pensamos ser de importância fundamental discutir os efeitos da universalização de termos e práticas discursivas, de regimes de verdade em cujo âmbito o próprio debate teórico e aquele localizado no campo da política sobre a relação aqui focalizada têm sido realizados.

A importância dessa discussão deve ser medida em vistas das consequências que as hegemonias obtidas tanto em relação aos modelos de desenvolvimento, quanto no que concerne às concepçóes do papel da cultura no enfrentamento dos pontos problemáticos nas diversas coletividades têm, na medida em que determinam decisivamente os processos nos quais vivemos e construímos ideias, práticas, cotidianos e utopias de sociedade - planos de erradicação da pobreza, maneiras de pensar o turismo, a formação educação básica e a produção acadêmica, a ciência, tecnologia, o espaço urbano, os modelos de mobilidade, de produção em todos os setores, os modelos de relação de gênero, dentre outros inúmeros elementos afetados. 


\section{0 campo imanente da cultura}

Cultura é um termo que conota tão diversos significados quantos são os autores e atores chamados a defini-lo. Para alguns, pode ser definida como música, pintura, teatro, cinema e dança, sendo algo relacionado com atividades artísticas, de entretenimento, que chamaremos aqui de definição estrita (AYOADE, 1989:5).

Os antropólogos alargam o escopo do significado dessa palavra, definindo-a como a totalidade das maneiras de viver de um povo, incluindo aspectos materiais e imateriais de sua vida, tais como vestuário, alimentos, crenças, maneiras de pensar, de morar, de se locomover, a linguagem, as religiões, instituições de todos os tipos, maneiras de sentir, tradições e costumes.

De acordo com Ortiz (2008), a cultura abrange todas as expressões materiais e não materiais de um povo, bem como os processos através dos quais elas são comunicadas, transmitidas, partilhadas. Ela envolveria todas as expressões e processos sociais, éticos, intelectuais, científicos, artísticos de um povo nacionalmente relacionado e normalmente ocupando e vivendo numa área geográfica delimitadas, incluindo o que e como eles os transmitem. Assim a cultura descreve semelhanças partilhadas entre pessoas dentro de um território físico ou emocional, que as fazem experimentar um sentimento de unidade e de pertencimento que geralmente se desdobra em desejos de cultivo e de transmissão intergeracional.

Destacando um outro aspecto importante, Shoremi (1999: 94) afirma que toda cultura é um conjunto de técnicas para possibilitar a convivências com os outros que dela fazem 
parte e com contextos a ela exteriores. $\mathrm{O}$ modus operandi $\mathrm{da}$ cultura implica na aquisição negociada de certos traços e de maneiras de adaptação e adequação pelos indivíduos que nela nascem, o que se reflete nas coletividades por eles compostas.

Um traço que não deve ser esquecido é seu poder regulador sobre a vida dos indivíduos que nela emergem, dela fazendo parte de forma ativa e passiva, moldando, sobretudo inconscientemente, suas atitudes, valores, emoções, objetivos, corporalidades, comportamentos e sua personalidade. Os homens e mulheres, os grupos dos mais diferentes tipos que eles constituem, existem dentro e através da mediação da cultura.

Nas décadas de 50 e 60 do século passado, o papel da cultura no desenvolvimento recebeu uma atenção considerável dos estudiosos de várias áreas e dos defensores da teoria da modernização. As explicações que eles produziam tomavam a noção de cultura como um sistema autorreferente de traços que distinguem uma comunidade/região de outra (Cf. BAUMAN, 1973, p.35), baseando-se no pressuposto de que sociedades modernas e tradicionais podiam ser definidas uma em oposição a outra, sendo os traços culturais ligados ao polo da tradição um obstáculo à indução/produção do desenvolvimento. Uma variante dessa abordagem reconhecia os estágios intermediários, vendo a relação tradição - modernidade como um contínuo (Cf., por exemplo, LERNER, 2002).

Neste texto, gostaríamos de pensar com os leitores a partir de uma definição de cultura inspirada nos estudos culturais, na qual as relações de poder são o elemento conceitual central, o que se desdobra numa definição de cultura como uma rede de representações - imagens, concepções de aspectos materiais 
e não materiais da vida social, conversações, códigos de comportamento, e as estruturas narrativas que organizam esses elementos, os quais moldam todos os aspectos da vida social (Cf. FROW; MORRIS, 1993, p.viii).

Colocando as relaçóes de poder como elemento central da conceituação de cultura, os estudos culturais também fornecem uma chave de análise da relação cultura-desenvolvimento que passa pela problematização das desigualdades globais e das metanarrativas que dão sustentação ao estabelecimento histórico de uma hierarquização dos países, culturas e seus modelos de desenvolvimento, em cujo âmbito as posições estruturais de poder determinam políticas de investimentos financeiros e de propostas de mudanças culturais discursivamente apresentadas enquanto caminhos para a produção/ indução do desenvolvimento.

A formulação proposta por Hall (1992) sobre $o$ Leste e $o$ Resto é um exemplo de articulação dessa definição de cultura aplicada ao estudo das desigualdades globais. A expressão que ele utiliza expressa as relações de poder entre as sociedades industrializadas ricas do Leste Europeu e dos Estados Unidos e os países subdesenvolvidos e em desenvolvimento, descritos como $o$ Resto. Ele descreve essas relações em termos de um sistema de representações discursivas poderosamente pervasivo, o qual tem construido os países que não fazem parte das regióes acima citadas como inferiores, e vai orientando e influenciando uma economia política que coloca em relação os desenvolvidos, os subdesenvolvidos e os em desenvolvimento.

Um ponto central da reflexão aqui proposta é a necessidade de desnaturalizar os discursos que constroem/constituem alguns países/algumas regióes como superiores, como 
modelos de imitação, os quais subjazem ao conhecimento autorizado sobre o mundo e seu funcionamento. Esse conhecimento é dominado, em termos da relação entre países, pelas imagens construídas e originadas nos países do Leste Europeu e Estados Unidos (também denominados paises do Norte) sobre si mesmos e sobre o Resto (Cf. HALL, idem).

Esses discursos fundamentam a estruturação dual do planeta, segundo a qual, os países do Norte, os desenvolvidos, transformam-se na medida de comparação, sendo os outros países/regiões definidas a partir desse espelho, que projeta características tais como modernização, industrialização, educação, eficiência, limpeza, democracia, urbanização, civilização, avanço, desenvolvimento, organização, dentre outras. A autodefinição dos países do Norte tem se transformado, no campo das decisões políticas e mesmo numa determinada área dos estudos sobre desenvolvimento, no modelo a ser perseguido pelos países do Sul (subdesenvolvidos, do Terceiro Mundo, em desenvolvimento, e, mais recentemente, os emergentes).

Como os paises do Norte conseguiram impor essa hierarquização e essa autodefinição enquanto modelo a ser seguido pelo Resto? Uma das respostas dadas por Hall (idem) aponta para a capacidade exercitada por eles para estabelecer um regime de verdade que instalou uma sintaxe, uma semântica, um vocabulário da superioridade do modelo ocidental de desenvolvimento, para o qual contribuíram decisivamente os processos de colonização europeia.

Podemos também agregar a integração midiática global que tem disseminado o modo de vida americano como o sonho inescapável para todo o planeta e, por último, a própria hegemonização de um debate construído no âmbito da teoria 
do desenvolvimento, em suas variações econômicas, sociológicas e antropológicas ${ }^{3}$. As maneiras pelas quais esse regime de verdade tem ressonâncias na reflexão das diversas disciplinas e das esferas governamentais regionais, nacionais e supranacionais sobre o desenvolvimento é o que focalizaremos, depois de uma breve exposição das contribuições foucaultianas, às quais estamos recorrentemente aludindo neste texto.

\section{Foucault, os discursos e as relações de poder}

A apresentação que fazemos da contribuição foucaultiana para a reflexão sobre a produção de discursos em geral em sua relação com o poder, não tem a pretensão de ser exaustiva, porque não é esse o objetivo do texto, nem haveria espaço para isso, mas tem uma finalidade operacional: a de colocar à disposição dos leitores nosso entendimento de conceitos daquele autor os quais utilizamos na reflexão que propomos sobre a relação entre cultura e desenvolvimento.

A produção dos discursos como um elemento fundamental da constituição de relações de poder foi um objeto privilegiado na obra de Foucault (1987a, 1987b e 1996). Para ele, o discurso é composto por um conjunto de ideias que

3 É preciso também levar em consideração a reprodução dessa hierarquização dentro dos países, das regiões (em termos geopolíticos) e mesmo de instituições politerritoriais. Ver, por exemplo, as relações hierárquicas, mediadas pelas práticas discursivas e regimes de verdade específicos, entre regiões Sul/Sudeste e o resto - as regiões Norte/Nordeste, no Brasil; entre os campi universitários da sede (às vezes, a capital) e os campi do sertão, no caso das Universidades que adotam o estilo multicampi, na Paraíba. 
condicionam as práticas sociais, devendo ser entendido como uma rede de relações na qual os sujeitos, grupos, instituições, sociedades estão envolvidos.

Na visão desse autor, o discurso não é um produto da retórica e não pode ser analisado como se faz em relação à estrutura significativa de um texto. Sendo basicamente o oferecimento de sistemas de posições a partir dos quais os emissores e alvos da prática discursiva são convocados a se posicionar; de acordo com essa perspectiva, o discurso não provém de uma categoria causal, não tem uma autoria individual, não sendo produzido por algo ou alguém em especial.

Mais importante nessa formulação são as noções de mobilidade, aproximação, o modo como o discurso isola temas e objetos, e molda, reforçando ou constituindo conteúdos concretos, de acordo com "suas condições de possibilidade" (FOUCAULT, 1996: 13).

Um discurso não consistiria de uma peça completa em si mesmo, contendo os elementos tradicionais tais como afirmações, teses, desenvolvimento e conclusão, mas seria um conjunto de afirmaçóes, de desenvolvimentos e conclusões que constituiriam, com a contribuição de outros discursos, o que Foucault chama de formação discursiva, que implica em um conjunto de práticas discursivas, as quais têm como objetivo produzir sistemas de significados, sentidos e posições a partir das quais se fala e se escuta.

Em relação às práticas discursivas e à formação discursiva em que se produzem os significados e classificações relativos ao desenvolvimento, os significados de estar no Norte, de estar no Sul; de ser desenvolvido, moderno, industrializado; de ser subdesenvolvido, tradicional, rural, do terceiro mundo; emergente 
e todo o conjunto de termos que circulam na autointerpretação e nas narrativas dos outros, tudo isso implica em práticas, em lugares, em posições, através das quais, as políticas das agências multilaterais e dos próprios governos, elites e o restante das populaçóes locais se definem e se comportam em relação a si próprios e em relação aos outros.

Em resumo, uma formação discursiva inclui discursos produzidos por indivíduos em diferentes lugares institucionais. Sua organicidade não depende do fato de serem os discursos produzidos por um mesmo indivíduo, sujeito ou a partir de um mesmo lugar social. $\mathrm{O}$ mais importante é entender que a formação discursiva constrói uma rede de posições as quais podem ser ocupadas consciente ou inconscientemente pelos que produzem discursos em seu âmbito e pelos que são por eles construidos.

Ao utilizar a sintaxe, o vocabulário do discurso desenvolvimentista, o próprio uso do termo desenvolvimento já nos coloca dentro de um sistema de posições, tornando-nos potenciais autores de práticas discursivas que ganham significado e possibilidade de existência em referência à formação discursiva em cujo âmbito a retórica sobre desenvolvimento é possível (Cf. FOUCAULT, 1987a). Os discursos não se constituem enquanto sistemas fechados, mas se estruturam a partir da interdiscursividade, importando elementos de outros discursos e os ressignificando dentro de suas redes de sentidos. Assim, por exemplo, os discursos que constroem a Europa se baseiam nos referentes à Cristandade, constituindo-se por tradução, paródia, adaptação dos sentidos plausibilizados naquele discurso-matriz. 
Os discursos que compõem uma formação discursiva não precisam ser iguais, mas as relações e diferenças que eles estabelecem devem ter regularidade. É o que Foucault chama de sistema de dispersão (FOUCAULT, 1987a). Assim, os discursos sobre desenvolvimento e as avaliações do favorecimento ou obstacularização que as culturas locais produzem, as falas sobre as relações entre moderno e tradicional e outros pares semelhantes são diferentes, mas reproduzem diferenças e similaridades regulares.

Essas formações são comparadas com esquemas de conceituação, matrizes de produção discursivas que servem para classificar, fazer surgir diferenças e semelhanças, para visualizar e fundamentar certa ordem de coisas, qualquer que ela seja. Entre as coisas se estabelece algo que funciona como sua lei interna, mas há também a ordem que é estabelecida pelo olhar, pela grade conceitual, pela atenção a um ou outro aspecto; e, como não poderia deixar de faltar, há uma linguagem, mas ela não é requerida sob a forma da relação entre significante e significado, e sim como fruto do conjunto de condições e circunstâncias, das suas regras de formação, as quais tornam possível e regulamentam a formação discursiva: as superfícies de emergência que indicam as esferas sociais, políticas, econômicas e culturais em que ela emerge.

\section{0 campo de imanência do desenvolvimento}

Desenvolvimento é uma palavra multifacetada, que tem como imediatos cognatos os termos "crescimento", "progresso" e mais recentemente "sustentabilidade", "humano", "social". Quando usada por economistas, há uma tendência 
para utilizar indicativos tais como PIB, índices de produtividade de setores de atividades produtivas, o nível de desenvolvimento tecnológico, tudo direcionando para o alvo do crescimento econômico.

Outra vertente aponta para uma definição de desenvolvimento que inclui, além daqueles referentes ao campo econômico, aspectos sociais, políticos, ambientais, numa tentativa de estabelecer uma abordagem capaz de envolver aspectos quantitativos e qualitativos na definição do termo em pauta. Desse modo, desenvolver-se significaria não somente a melhoria dos aspectos materiais da vida dos indivíduos de uma determinada região/área/cultura, mas também assegurar-lhes o bem-estar social, incluindo a garantia da dignidade humana para todos, bem como o manejo racional, consequente democrático, humano e ético - do meio ambiente ( $C f$., por exemplo, SEN, 2000; SAHCS, 2004)

As ideias a respeito do que é ser desenvolvido brotam no imaginário das várias culturas a partir do regime de verdade instituído em torno da superioridade do Norte sobre o Sul, dos países centrais do sistema mundial do capitalismo. Assim, os padrões culturais locais sofrem as pressões inescapáveis das culturas correspondentes aos países autodefinidos como desenvolvidos.

No planejamento urbano, nas definições arquitetônicas, na organização dos planos de turismo, na configuração dos menus dos restaurantes, no delineamento dos equipamentos e serviços dos hotéis, na conformação das políticas de publicação científica e de operacionalização dos modelos de educação em todos os níveis, dentre outras áreas da vida social, todo o mundo é pressionado para adotar os modelos instituídos 
pela mediação de práticas discursivas possíveis no âmbito do regime de verdade estabelecido pelos países autodenominados de desenvolvidos - os do Norte - a respeito do desenvolvimento e das maneiras de induzi-lo.

Ferguson (1994) discute como o regime de verdade em cujo âmbito florescem os discursos desenvolvimentistas, cria um campo de imanência favorável à produção de versões descritivo-avaliativas sobre as comunidades, regióes, países fora do centro do capitalismo mundial, que possibilitem os agentes especializados em desenvolvimento - desde os ligados à macro-organização da economia mundial, tais como o Banco Mundial, o FMI o BID, a própria UNESCO -, quanto aqueles atuando no meso/micro nível, a saber, as diversas ONGs, os professores universitários/coordenadores de projetos de desenvolvimento, dentre outros, conquistarem sua plausibilidade.

A formação discursiva em cujo âmbito são produzidas e disseminadas as práticas discursivas que tematizam o desenvolvimento, colocam em operação um inconsciente social que seleciona representaçôes dos lugares, comunidades, regiôes, países, que possibilitem o encaixe entre o que os agentes especializados oferecem enquanto projetos, modelos, estratégias e as necessidades construídas pelas narrativas advindas tanto do campo da políticas quanto do campo da ciência.

Essas narrativas/descrições construídas em relações a cenários nacionais, regionais e locais, apresentadas como neutras, tecnoburocráticas, funcionam como fornecedores de abundantes sinapses sociais para a constituição das agências 
de desenvolvimento em seus mais diversos níveis ${ }^{4}$ enquanto necessárias, imprescindíveis e, frequentemente, mobilizam a culpabilização da cultura local, que passa a ser descrita como tradicional, atrasada, resistente a mudanças e pouco empreendedorista - tudo isso sendo, às vezes, traduzido em termos de posse de baixo capital social.

\section{A evolução da retórica desenvolvimentista na direção da inclusão da cultura}

Textos produzidos por agências multilaterais são excelentes como provedores de sintomas dos fenômenos que explicitamente buscam focalizar, ao mesmo tempo em que oferecem uma síntese de discussões e consensos estabelecidos a partir de ampla consulta internacional, em contextos marcados por relações assimétricas de poder.

O documento intitulado Towards a UNESCO culture and development indicators suite (2009) - (Em direção de um conjunto de indicadores sobre Cultura e Desenvolvimento da UNESCO), oferece alguns elementos para entender como a retórica sobre Desenvolvimento muda na superfície, embora

4 Insistimos neste ponto dos diversos níveis dos agentes especializados, como citados acima, para evitar aquela visão já devidamente criticada de pensar os problemas sociais em termos da relação entre centro e periferia, significando os países do centro e da periferia do capitalismo. Sem negar os efeitos das hierarquizações em termos de países/estados-nações, lembramos que nas economias nacionais, entre regiões; das regiões, entre estados; nos estados, entre as cidades/microrregiões que os compõem, ou mesmo dos territórios (no sentido geopolítico), o raciocínio apresenta o mesmo poder argumentativo, guardadas as devidas proporções, evidentemente. 
no mais profundo permaneça inscrita nos regimes de verdade e práticas discursivas formulados na sua origem.

Comecemos pelo início do texto:

Durante os 60 anos passados, apoiar e assegurar o desenvolvimento dos países pobres tem sido uma das principais prioridades da comunidade internacional. Investimentos significantes têm sido feitos em termos de ajuda e infraestrutura, acompanhados de modelos propostos para dar suporte ao crescimento econômico e ao desenvolvimento sustentável. (UNESCO, 2009, p.1)

Se não houvesse a intenção de mascarar a matriz discursiva aqui implícita, o texto colocaria em relação de oposição à expressão países pobre a expressão países ricos. Usando um recurso eufemístico, destinado a mascarar o estilo que caracterizou, durante muito tempo, a retórica sobre desenvolvimento, é utilizada a expressão comunidade internacional, que remete a uma entidade global, sem vestígios da hierarquia geopolítica que marca de modo indelével as relações entre países e blocos de economias nacionais.

Muitos exemplos históricos têm sido apresentados dos efeitos perversos dessa ajuda internacional. Os teóricos da dependência, bem como autores vinculados aos Estudos Culturais têm mostrado as relações de força e de exploração que foram mediadas pelo que foi propagandeado como ajuda internacional para o desenvolvimento (ver, por exemplo, FERGUSON, 1994). 
Uma avaliação da história do Desenvolvimento escrita nos últimos 60 anos, qualquer aprofundamento pretendido obrigaria os analistas a reconhecerem a preocupação com o crescimento econômico (nem sempre dos países-alvos dos programas de ajuda internacional para o desenvolvimento), mas de nenhuma maneira o suporte ao desenvolvimento sustentável, pelo menos no sentido que os autores desse conceito pensaram o modelo.

O documento então se volta para a questão da redefinição do papel da cultura na retórica sobre desenvolvimento:

Até recentemente, a cultura não tinha sido levada em consideração em tais investimentos ou modelos: realmente a ideia que a cultura deveria desempenhar um papel importante nos processos de desenvolvimento teve uma recepção mista pelos atores e agências-chave na comunidade internacional do Desenvolvimento. (UNESCO, 2009, p.1).

Mais uma vez o texto busca construir uma visão neutra, asséptica dos processos de promoção do desenvolvimento, infelizmente nem sempre tão suaves. A impressão que se pode ter é que a cultura, de forma geral, não tinha seu papel importante reconhecido nas formulações anteriores da retórica desenvolvimentista. Mais uma vez a análise histórica dos usos da teoria da modernização, formulação segundo a qual a cultura podia ser considerada como aliada ou obstáculo da chegada de uma dada economia aos padróes desejados de industrialização, de integração com o mercado, só para citar alguns dos 
alvos previstos, facilmente demonstra a superficialidade da argumentação aqui apresentada.

Ao contrário do que é afirmado, sempre houve nos discursos e práticas desenvolvimentistas uma preocupação com e o reconhecimento da importância do papel da cultura. A própria disseminação da classificação que elevou os países do Norte da Europa e os Estados Unidos como modelos, e o Resto como atrasados, subdesenvolvidos constituiu-se numa metanarrativa que penetrou de modo pervasivo as culturas de todo o mundo, com efeitos e ressonâncias poderosamente entranhadas (Cf. HALL, 2000).

O que precisamos entender é como se constrói e o que significa a nova postura diante do papel da cultura nessa retórica sobre o desenvolvimento. Vejamos como isso vai sendo comentado no documento da UNESCO aqui analisado, no seguinte trecho, que desemboca na seção intitulada a inclusão da cultura no desenvolvimento internacional:

A hegemonia do modelo da Modernização foi significativamente desafiada, entretanto, pela crise econômica dos anos de 1980, quando os países em desenvolvimento foram particularmente afetados. Essa situação tanto expôs as fraquezas como levou a uma reavaliação dos objetivos e métodos da cooperação internacional para o desenvolvimento. Como um resultado, novas abordagens do desenvolvimento alargaram o foco, para incluir junto do crescimento econômico, investimento na alfabetização, educação, agricultura e igualdade de gênero. (UNESCO, 2009, p.1). 
No cenário da ajuda internacional para o desenvolvimento dos anos 1980, um dos elementos mais importantes foi o financiamento oferecido pelo Banco Mundial e pelo Fundo Monetário Internacional para os chamados paises desenvolvidos. Como afirmado acima (concordando com FERGUSON, 1994), os discursos desenvolvimentistas se constroem de maneira a encaixar as habilidades e produtos oferecidos pelas agências internacionais de promoção do desenvolvimento. A retórica desenvolvimentista de então estabelecia como passos necessários ao crescimento econômico uma série de ações no sentido de promover a industrialização, urbanização e integração ao mercado mundializado. Os altos juros e a sangria de recursos para pagamento das dívidas, aliados às maneiras de incorporação das economias desses países ao sistema de produção mundial, ao invés de contribuírem para a realização das promessas de desenvolvimento, agravaram os problemas sociais e as desigualdades nos países em desenvolvimento.

A incorporação das novas variáveis à retórica desenvolvimentista, sob a bandeira da inclusão da cultura, deve ser compreendida em referência à instalação de novos pontos de encaixe com as novas habilidades das agências internacionais, as quais passam a oferecer uma nova versão para justificar a necessidade de suas intervenções no sentido de promover o desenvolvimento. É interessante como o texto aponta inadvertidamente para o que parece ser a realidade da reformulação proposta:

As experiências acumuladas ao longo dos anos apontaram para a necessidade de incluir no desenvolvimento todos os fatores que aprontam as sociedades para as intervenções em direção da sustentabilidade. (UNESCO, 2009, p. 2, negrito nosso). 
Nesse trecho, vale a pena destacar dois pontos: o primeiro, a declaração explícita da funcionalidade subjacente às novas produções discursivas relativas ao desenvolvimento: aprontar a sociedade para as intervençôes. É como se os efeitos dos discursos resultassem na abertura das portas para a entrada da ação interventiva dos profissionais da promoção do desenvolvimento (conforme argumentação apresentada acima); o segundo, a emergência do novo conceito em torno do qual as agências desenvolvimentistas em todos os níveis vão oferecer suas contribuições em termos de ações indutoras, a saber: a sustentabilidade.

O escopo deste capítulo não comporta uma análise aprofundada do conceito do desenvolvimento sustentável. Sobre isso diremos apenas, concordando com o destacado por Fernandes (2003), que a emergência do modelo do desenvolvimento sustentável, com sua ênfase na necessidade de combinar o crescimento econômico com a gestão racional dos recursos naturais e a preocupação com a equidade social, cultura e espaço, funciona, na prática, para manter intocados o reino e o ritmo da economia mundial. Seus desdobramentos em termos de retóricas da defesa de políticas de revalorização das culturas tradicionais nos países classificados como em desenvolvimento e subdesenvolvidos, reabastecem os pontos de encaixe das agências de desenvolvimento em todos os seus níveis.

Graças à mediação dos discursos sobre o Desenvolvimento Sustentável, a Amazônia tornou-se um extenso espaço para investimentos e implementação de programas, projetos e pesquisas voltados para a preservação do meio ambiente e experiências sustentáveis. Financiados pelo Fundo para o Meio Ambiente Global - GEF (Global Environment Facility), vinculados ao Experimento de Grande Escala denominado Biosfera-Atmosfera - LBA (The Large Scale Biosphere- 
Atmosphere Experiment in Amazônia) e abrigados no Programa Piloto para a Proteção das Florestas Tropicais do Brasil - PPG-7 (The Pilot Program to Conserve the Brazilian Rain Forest), dentre outros, ou promovidos por Universidades e Centros de pesquisa (ver quadro abaixo, com lista de algumas das principais Agências Internacionais de Cooperação para o Desenvolvimento), a partir de 1995, na Amazônia legal, houve um aumento significativo de programas e projetos ambientais provenientes de acordos de cooperação internacional, que têm como proposta "reduzir a pobreza" e "preservar o meio ambiente" (Cf. FERNANDES, 2003; PRESSLER; PEDREIRA, 2010; VEIGA, 2008).

No exemplo da Amazônia, podemos observar como o que pode ser denominado de colonização pós-moderna é realizado com a mediação suave e politicamente correta da retórica desenvolvimentista da sustentabilidade, dos discursos de preservação do meio ambiente, respeito às culturas locais e combate à pobreza. Para ilustrar essa ideia, vejamos excertos desses discursos:

\begin{tabular}{|c|c|}
\hline $\begin{array}{l}\text { GTZ - Alemanha } \\
\text { Cooperação Técnica } \\
\text { Alemã }\end{array}$ & $\begin{array}{l}\text { "Nossa missão é mudar a atual realidade através } \\
\text { do apoio ao desenvolvimento e adoção de sistemas } \\
\text { sustentáveis de manejo florestal na Amazônia". }\end{array}$ \\
\hline $\begin{array}{l}\text { USAID - Estados Unidos } \\
\text { Agência dos Estados } \\
\text { Unidos para o } \\
\text { Desenvolvimento } \\
\text { Internacional }\end{array}$ & $\begin{array}{l}\text { "Nosso objetivo é assistir ao governo e à sociedade } \\
\text { por meio de programas de qualidade que fomentem } \\
\text { o desenvolvimento social e econômico sustentável, } \\
\text { preservem o meio ambiente e que busquem mitigar } \\
\text { a disseminação de problemas transnacionais". }\end{array}$ \\
\hline $\begin{array}{l}\text { DFID - Reino Unido } \\
\text { Departamento para } \\
\text { o Desenvolvimento } \\
\text { Internacional }\end{array}$ & $\begin{array}{l}\text { "Nossa ação se destina a promover o desenvol- } \\
\text { vimento sustentável, para eliminar a pobreza do } \\
\text { mundo". }\end{array}$ \\
\hline
\end{tabular}

Adaptado de quadro elaborado por Pressler \& Pedreira (2010), com base em material institucional das respectivas agências. 
Como pode ser observado acima, a semelhança e regularidade das diferenças que subjazem aos discursos ligados ao novo registro do modelo do desenvolvimento sustentável das agências internacionais de cooperação internacional (mas também aos discursos das agências nacionais, regionais e locais profissionalizadas na promoção do desenvolvimento) testemunham a continuidade do regime discursivo em cujo âmbito foram produzidas as práticas discursivas relativas à atualmente demonizada teoria da modernizaçãos.

O que é narrado enquanto despertamento para a importância da cultura, como vemos no trecho do documento da UNESCO citado a seguir, dificilmente incomodará a lógica inexorável do mercado, da preocupação com os índices de crescimento da economia, dos Produtos Internos Brutos:

A cultura influencia fortemente todos os aspectos da vida diária pública e privada. Ela está profundamente interligada como todos os níveis dos processos de decisões

5 A roupagem é diferenciada, mas o sistema de diferenças replica o que estava presente na(s) matriz(es) discursivas dessa retórica: o Resto é traduzido pela expressão paises tropicais, que assim, como os subdesenvolvidos, os pobres, os atrasados, os tradicionais, precisariam a ajuda internacional para superar seus problemas; no da agência alemã, que prontamente, com isenção técnico-científico-burocrática, permanece a distinção entre desenvolvidos (capazes) e subdesenvolvidos/em desenvolvimento (incapazes) - aqui os analistas reconhecem o propagado respeito às culturas tradicionais, um dos motes do nova retórica da sustentabilidade, e às suas técnicas milenares específicas de manejo do meio ambiente, como uma pedra no meio do caminho do encaixe das práticas discursivas do modelo e a ação das agências cooperação internacional; no da USAID, se repete a classificação mencionada no comentário sobre o discurso da GTZ, que justifica a intervenção das agências especializadas internacionais, mas vale destacar a estratégia eufemística utilizada no trecho de finalização da citação: que busquem mitigar a disseminação de problemas transnacionais. 
políticos e econômicos, às mídias de massa e à educação, e aos seus impactos nas relações sociais. É ainda sua riqueza que fez com que políticas e programas de desenvolvimento sensíveis à diversidade cultural incluíssem e levassem em consideração a diversidade cultural. Um mesmo tamanho não pode servir para todos. (UNESCO, 2009, p. 2).

Um olhar mais sistemático sobre a conjuntura atual pode nos ajudar a desmontar, a resistir a essa celebração da inclusão da cultura nos programa e politicas de desenvolvimento. Se as práticas discursivas recentes, forjadas ao longo de quase três décadas de conferências, congressos, reuniões internacionais ${ }^{6}$, podem se dar ao luxo de afirmar a importância de respeitar

6 A partir de 1972, a UNESCO começou a estimular a realização de conferências internacionais e a produzir documentos sobre Políticas Culturais. Eis uma cronologia dos principais:

- 1975 - a Conferência Intergovernamental sobre Política Cultural na África afirmou a cultura como "uma condição sine qua non para o desenvolvimento, endógeno, compativel e equilibrado".

- 1982 - uma das principais consequências da Conferência Mundial sobre Política Cultural (Mondiacult), realizada no México, foi a declaração, pela Organização das Nações Unidas, da década do Desenvolvimento Cultural (1988-1997) .

- 1988 - Conferência Intergovernamental sobre Políticas Culturais para o Desenvolvimento.

- 1991 - Resolução da ONU que criou uma Comissão Mundial Independente sobre Cultura e Desenvolvimento, formada por mulheres e homens importantes em diversas disciplinas, indicados por todas as regiões do planeta, para redigir o Relatório Mundial sobre Cultura e Desenvolvimento, e também formular propostas de longo prazo para contemplar as necessidades culturais no contexto do desenvolvimento. 
as especificidades culturais de cada coletividade, é porque o trabalho de unificação de padrões de consumo em todas as áreas da vida social tem produzido um processo intenso de padronização e homogeneização global.

Longe de vivermos um momento da história mundial em que as culturas nacionais, locais se reafirmam em sua especificidade, valor e soberania, assistimos, graças à constituição das redes planetárias de comunicação computadorizada, à exacerbação histórica da unificação dos modelos de vida em nível mundial. Não negamos a existência de ilhas de resistência e de afirmação de traços culturais autóctones em vários pontos do sistema mundial, na periferia da hierarquia entre coletividades.

- 1996 - Publicação do relatório Nossa Criativa Diversidade, no qual podem ser encontradas pesquisas e estatísticas para fortalecer a colocação da cultura enquanto um elemento chave das teorias do desenvolvimento.

- 1998 - Conferência Internacional sobre Políticas Culturais para o Desenvolvimento - Estocolmo, Suécia, 30 de Março a 2 de Abril.

- 1999 - O Valor da Cultura - documento de posicionamento da UNESCO, apresentado no Fórum sobre Desenvolvimento e Cultura, realizado em Paris.

- 1999 - A cultura importa: Financiamento, Recursos e a Economia da Cultura no Desenvolvimento Sustentável. Conferência promovida pelo Banco Mundial, em Washington, DC.

- 2004 - Relatório da UNESC sobre o Desenvolvimento Humano, intitulado Liberdade Cultural no Mundo Diverso Atual, no qual é destacada a importância da cultura e do multiculturalismo nas políticas de desenvolvimento humano.

- 2009 - Relatório Mundial da UNESCO intitulado Investindo na Diversidade Cultural e no Diálogo Intercultural. 
Queremos chamar a atenção para o fato de que a própria idealização e apologia dos traços tradicionais das culturas nacionais, regionais - a exemplo das formas de extrativismo das quebradeiras de coco, do Pará; da música de Zabé da Loca, na Paraíba; das cisternas de placas, no semiárido paraibano - devem ser entendidas numa rede de mercadorização constituída pelas agências multilaterais, nacionais, regionais e locais de desenvolvimento, nas quais o controle, a comercialização do exótico, do tradicional, do ecologicamente correto são acirradamente disputados (Cf. FERNANDES, 2003).

Para concluir essa breve análise, gostaríamos de citar apenas mais um trecho, para apontar uma importante tendência na recente articulação entre práticas discursivas e não discursivas relativas ao desenvolvimento:

Todavia, esse discurso não tem sido tão influente como poderia ser (o da inclusão da cultura nas políticas e programas de desenvolvimento), e, assim, ao invés de restringir a sua ação perspectivas à avaliação do papel que a cultura pode desempenhar no desenvolvimento, a UNESCO também defende seu uso instrumental. Ao promover a cultura dessa maneira, a UNESCO está abrindo o caminho para práticas e modelos futuros, com o objetivo final de transformá-los em um setor totalmente reconhecido do desenvolvimento. A efetividade da cultura no desenvolvimento, demonstrada através da promoção das indústrias culturais, por exemplo, pode aumentar a atenção dada às riquezas culturais dos países em desenvolvimento e não apenas seus recursos naturais ou o poder econômico. (UNESCO, 2012, p. 4). 
Esse trecho é bem ilustrativo de uma das maneiras mais significativas de colocação da cultura em relação com o desenvolvimento. Aqui entendida em seu sentido estrito, a cultura vem sendo priorizada como foco crucial nas agendas dos programas de desenvolvimento, permeando as temáticas de diversos segmentos de Estado, expandindo suas vertentes como alicerce estratégico, na medida em que é reconhecida sua potencialidade de capitalização, seu valor de mercado ( $C f$. MARCO, 2010).

De modo semelhante ao que aconteceu com os recursos naturais diversos, com as paisagens, com os artigos científicos, com a Educação, com a Saúde, todos os aspectos da vida social, que foram gradualmente transformados em mercadorias, em capital, observamos o crescimento da importância da cultura na relação com o desenvolvimento pela emergência do que passa a ser denominado de economia da cultura ou de economia do entretenimento - que inclui os resultados as atividades artísticas e intelectuais, a exemplo das indústrias fonográficas, audiovisuais, editoriais, os equipamentos culturais tais como museus, teatros, cinemas e redes informáticas -, que equipara a cultura aos outros segmentos das indústrias tradicionais, no que diz respeito à lógica numérica dos grandes mercados, na incidência dos índices monetários ( $C f$. CANCLINI \& MONETA, 1999).

Assim considerada, a cultura, enquanto arte, ciência e filosofia, bem como no seu sentido amplo, passa a ser vista como meio de indução de desenvolvimento, na medida em que, gerando postos de trabalhos diretos e indiretos, colocando em circulação recursos e investimentos de modo semelhante ao que acontece em outros ramos de atividades econômicas 
tradicionais, pode se integrar como mais uma variável do desempenho econômico de uma determinada coletividade (Cf. YÚDICE, 2004).

\section{Uma proposta de agenda de pesquisa}

Na elaboração de sugestões para uma agenda de pesquisa sobre a temática aqui focalizada, partimos, inicialmente, do questionamento da retórica desenvolvimentista. Algumas propostas para o estabelecimento de variáveis e indicadores para medir e, ao nosso ver, controlar os investimentos locais, mas sobretudo, aqueles anunciados enquanto ajuda internacional para o desenvolvimento, têm sido produzidas por vários países. Nessas propostas, são patentes as marcas das práticas discursivas da retórica desenvolvimentista que inspirou as estratégias históricas de cooperação entre os países do Norte e os do Resto do mundo ${ }^{7}$.

Nosso desafio, a partir deste ponto do texto, é testar a possibilidade de construir novas maneiras de falar sobre as dinâmicas pelas quais as coletividades podem enfrentar suas dificuldades, os problemas considerados dignos da atenção

7 Para checar essa interpretação, sugerimos a consulta do documento Towards a UNESCO Suite of indicators on Culture and Development (2009 - 2010): Literature review (February 2010), disponível no link: http://www.unesco.org/new/fileadmin/MULTIMEDIA/HQ/CLT/ pdf/Conv2005_CDindicators_Literature.pdf

Esse documento mereceria uma análise específica, impossível de ser feita aqui pela exiguidade de espaço, por ser uma síntese das maneiras pelas quais o alegado novo lugar da cultura na retórica desenvolvimentista tem sido construído. 
coletiva, é o ponto central do esforço que os cientistas, bem como outros atores socialmente construídos poderiam fazer, para, inclusive, reinventar maneiras pelas quais tanto a produção artística quanto o conhecimento disponibilizado da moldagem cultural, dos sistemas de posições e relações de poder que conjuntos de indivíduos estabeleceram nas quais foram e continuam sendo constituídos podem contribuir para a construção de ordens sociais mais satisfatórias para todos ${ }^{8}$.

A partir desse ponto fundamental, alguns temas gerais poderiam mobilizar nossos esforços intelectuais:

- Mudanças e transições pelas quais as coletividades focalizadas estejam atravessando, devidas às transformações dos cenários internos e externos. Aqui consideramos importante, na reflexão sobre as relações de poder constituídas nos processos de discussão e de reestruturação neles forjados, a rationale das resistências eventualmente encontradas. Pensar as dinâmicas pelas quais as políticas identitárias emergem, suas aspirações e utopias, bem como as maneiras pelas quais as construções de subjetividades dos atores e grupos de

8 Neste sentido, abordagens como a de Dan Baron, em seu livro Alfabetização cultural - a luta intima pela transformação da bumanidade, no qual são apresentados e propostos exercícios de aplicações práticas, pode oferecer excelentes insights para o enfrentamento individual e coletivo de barricadas culturais erguidas pela exposição continuada a práticas discursivas mediadoras de sistemas autoritários de posições, inclusive pela construção de espelhos desfavoráveis de identificação cultural. Sugerimos também o livro de James Scott (1985) Weapons of the Weak, no qual, a resistência cultural é focalizada não como um obstáculo ao bem-estar social, mas como uma necessidade histórica para a operacionalização do questionamento de ordenamentos sociais injustos. 
autores envolvidos se operacionalizam, pode ser muito útil se o objetivo é realizar tudo com o mínimo possível de fascismo dentro de nós (Cf. FOUCAULT, 1977).

- Diferenças e conflitos entre culturas e subculturas, entre as fronteiras das identidades culturais historicamente construídas.

- Contextos e cenários em que se constroem as desigualdades permanentes, em termos de estruturas, regras, limitadores, agências. Escolhas, sistemas de valores e modelos de organização social.

\section{A questão do escopo das políticas culturais}

Embora reconheçamos que os fatores culturais desempenham um papel importante em todas as esferas da formação de políticas públicas, às vezes limitamos nossas definições de políticas culturais como sendo direcionadas apenas para aquelas instituições públicas que atuam no setor das artes $\mathrm{e}$ do entretenimento. Isso significa uma definição restritiva e pouco ampla, na medida em que setoriza a focalização, ao invés de estender a definição de política cultural de modo a relacioná-la com áreas tais como o meio ambiente e a economia, permeadas pelos significados e valores culturais.

A conceituação de políticas culturais deveria também incluir todas as organizações, quer públicas ou privadas, envolvidas com a produção e distribuição de bens e serviços culturais, bem como com a gestão dos recursos culturais. Os dois setores são igualmente importantes do ponto de vista das políticas públicas, sendo melhor entendidos quando 
colocados em relação. Vale também lembrar que as políticas públicas se referem tanto à cultura de massas quanto à cultura erudita , ambas consideradas igualmente importantes.

Nessa área da organização da esfera da cultura (em sentido estrito), sugerimos como elementos importantes para a pesquisa especializada:

\section{As políticas culturais governamentais, tanto no nível nacional quanto nos regionais e locais - as quais impactam a composição e operações do setor cultural}

Como tópicos específicos, poderíamos listar:

- As decisões relativas à alocação de recursos públicos nas instituições culturais;

- As formas de gestão dessas instituições públicas;

- O acesso à produção financiada por recursos públicos;

- A regulação das concessões de canais de mídia;

- A regulação da operação das diversas mídias - classificação, censura e etc.;

- A questão dos direitos autorais na dinâmica da indústria cultural;

- As políticas culturais e as novas tecnologias informacionais e comunicacionais;

- O bem-estar cultural como um indicador da qualidade de vida;

- O acesso aos recursos culturais e processos de construção de cidadanias; 
- As leis gerais e regulamentações específicas concernentes à propriedade intelectual;

- O papel das artes, das instituições de produção e distribuição de bens e serviços culturais nas agendas do planejamento urbano, rural e regional.

\section{As políticas culturais desenvolvidas pelas instituições culturais}

As maneiras pelas quais elas levam em consideração tanto o ambiente comercial quanto o contexto de políticas públicas nos quais elas atuam. Isso implica levantar dados sobre a articulação entre o papel das políticas culturais nas instituições públicas e privadas da cultura, no que se refere à tradução dos pontos das políticas de contextos mais amplos na dinâmica de distribuição de bens e serviços culturais. Como as comunidades distantes dos centros geopolíticos em nível, local, regional e nacional são envolvidas nas iniciativas governamentais de ampliação e disponibilização das redes de comunicação, e com quais consequências? Como a indústria cultural privada responde às medidas governamentais para estimular seu desenvolvimento econômico? Quais os efeitos das isenções tributárias como incentivo ao investimento privado na economia da cultura? Essas questões são fundamentais para entender a interface entre os governos e os níveis institucionais das políticas culturais, para inclusive possibilitar a avaliação das políticas públicas na área. 


\section{As influências da sociedade civil organizada na formulação de alternativas de políticas culturais e seus resultados}

Compondo a sociedade civil na interface com a construção das políticas culturais estão ONGs, defendendo programas culturais para determinados grupos sociais ou grupos de produtores; associações de cidadãos que atuam politicamente reivindicando na área dos padrões morais da produção cultural; fã-clubes que exercem pressão por melhores formas de apoio a tipos específicos de atividades culturais; movimentos sociais organizados lutando para manter e promover a cultura de minorias étnicas ou lutando pela igualdade de direitos relativa a gênero, orientação sexual; partidos políticos, com suas orientações na área da cultura; grupos religiosos, dentre outros.

Qualquer que seja o caso, é através da ação dessas organizações que os processos de formação de política pública na área são submetidos às demandas e pressões da vida social, com suas urgências e contradições, podendo se vincular a processos de enfrentamento de problemas que as coletividades considerem dignos de atenção pública. Esses são atores reais atuando no processo de construção das políticas públicas pela enunciação das demandas coletivas, e que podem servir como rotas através das quais, as políticas culturais podem se conectar com a vida social, ao atendimento das demandas culturais e a solução dos problemas coletivos. 


\section{Avaliação dos resultados das políticas culturais no que se refere à qualidade e quantidade dos bens, serviços e processos que elas contribuem para disparar}

A avaliação dos resultados envolve pesquisar as maneiras e as condições de acesso dos diferentes grupos sociais à produção e circulação de bens e serviços culturais. Dependendo das circunstâncias, os indivíduos podem ser vistos sob diferentes perspectivas: como produtores, mediadores, distribuidores, consumidores, como públicos ou como comunidades - alvo. Essa variedade de perspectivas é inevitável e mesmo desejável, dada a variedade, pluralidade e complexidade das maneiras pelas quais os bens e serviços culturais são produzidos, comercializados, distribuídos e consumidos.

Em todo caso, porém, a pesquisa é necessária para revelar quão diferentes são os contextos abrangidos pelas políticas públicas culturais e seus impactos sobre os padróes atuais de distribuição de bens e serviços culturais, explorando, inclusive, as dimensões qualitativas das maneiras pelas quais os diferentes grupos e indivíduos experienciam, interpretam e avaliam as atividades culturais de que participam.

Para finalizar, pensamos que é necessário um esforço especial de pesquisa no que se refere à conexão entre políticas culturais e solução de problemas das coletividades, bem como para expandir as possibilidades de realização dos indivíduos e grupos delas participantes. Há várias perspectivas a partir das quais essas conexões podem ser pensadas: as dinâmicas das indústrias culturais; a focalização dos direitos culturais e relativos à cidadania e ao respeito das diferenças; as dinâmicas da diversidade cultural; as atividades culturais no planejamento do bem-estar urbano e rural; a relação entre cultura e identidades coletivas, 
dentre outras. Reafirmamos aqui que não se trata de proteger culturas, resguardar as identidades culturais de determinadas coletividades. No exemplo da produção cinematográfica, por exemplo, não consideramos possível, nem desejável, regular o contato, o consumo de filmes a partir das nacionalidades, todavia, o estado pode atuar no sentido de impedir que problemas tais como a cartelização e a constituição de monopólios de produção e distribuição inviabilizem a possibilidades de produção e circulação das produções nacionais.

As políticas culturais podem atuar, portanto, no sentido de garantir o respeito e as condições de existência e expressão das culturas das diversas coletividades colocadas em relação, contribuindo para combater o imperialismo e o colonialismo cultural em qualquer nível: evitando, nas universidades, a sobrevalorização de linguagens e campos de circulação da produção científica em detrimento, às vezes, dos próprios a partir dos quais a produção regional, nacional se origina; no campo do gênero, combatendo o sexismo, o heterocentrismo, além de todas as formas de racismo e discriminação.

As políticas culturais públicas podem atuar no sentido de construir espaços nos quais o entendimento liberal e plural da cultura prevaleça! Não há espaço para nenhuma ilusão de neutralidade associada à palavra cultura, como também a expressóes tais como problemas da coletividade. Em tempos de integração cultural global, as políticas culturais públicas desempenham um papel de alta relevância no estabelecimento de regras que garantam equidade e igualdade de direitos nas relações entre maneiras humanas diferentes de viver, ao mesmo tempo em que podem contribuir para a aproximação das coletividades das utopias relativas a todas as áreas da vida social que elas forem capazes de construir. 


\section{Referências}

AYOADE, J. The cultural debate in Africa. The Black Scholar, v.20, n.5,1989.

BARON, Dan. Alfabetização cultural - a luta íntima pela transformação da humanidade. São Paulo: Alfarrábio, 2004.

BAUMAN, Zygmunt. Culture as Praxis. London:

Routledge \& Kegan Paul, 1973.

CANCLINI, Néstor García \& MONETA, Carlos Juan (orgs.). Las industrias culturales em la integración latinoamericana. México: Grijalbo, 1999.

CRUSH, J. (ed.) Power and Development. London \& New York: Routledge, 1995.

ESCOBAR, Arturo. The Problematization of Poverty: the Tale of Three Worlds and Development. In Susanne Schech $\&$ Jane Haghins (eds.). Development - a Cultural Studies Reader. Oxford, UK: Blackwell Publishing, 2002.

FERNANDES, Marcionila. Desenvolvimento Sustentável: antinomias de um conceito. In Marcionila Fernandes \& Lemuel Guerra (orgs.) Contra-Discurso do Desenvolvimento Sustentável. Belém: Associação de Universidades Amazônicas, 2003. p.131-169.

FERGUSON, James. The Anti-Politics Machine: “Development", Despolitization, and Bureaucratic Power in Lesotho. Minneapolis \& London: Oxford University Press, 1994. 
FERGUSON, James. The Constitution of the Object of

Development: Lesotho as a "Less Developed Country. In Susanne Schech \& Jane Haghins (eds.). Development - a Cultural Studies Reader. Oxford, UK: Blackwell Publishing, 2002.

FOUCAULT, M. A Arqueologia do Saber. Rio de Janeiro: Forense Universitária, 1987a.

FOUCAULT, M. As Palavras e as Coisas. São Paulo: Martins Fontes, 1987b.

FOUCAULT, M. A Ordem do Discurso. São Paulo: Edições Loyola, 1996.

FOUCAULT, Michel. Preface. In: Gilles Deleuze e Félix Guattari. Anti-Oedipus: Capitalism and Schizophrenia. New York: Viking Press, 1977, pp. XI-XIV.

FROW, J. \& MORRIS, M. (eds.) Australian Cultural Studies: a Reader. St. Leonards, NSW, 1993.

HALL, Stuart. The West and the Rest: Discourse and Power. In S. Hall \& B. Giebens (eds.) Formation of Modernity. Cambridge: Polity Press, 1992.

HARRISON, L.E. Introduction: Why culture matters. In Culture matters: How values shape human progress. L.E. Harrison \& S.P. Huntington (eds.) New York: Basic Books, 2000. 
HERMET, Guy. Cultura e Desenvolvimento. Petrópolis, RJ: Vozes, 2002.

HUNTINGTON, S.P. Foreword: Cultures count. In Culture matters: How values shape human progress. L.E. Harrison \& S.P. Huntington (eds.) New York: Basic Books, 2000.

LANDES, D.S. Culture makes almost all the difference. In Culture matters: How values shape human progress. L.E. Harrison \& S.P. Huntington (eds.) New York: Basic Books, 2000.

LERNER, Daniel. Modernization Ideals, in Susanne Schech \& Jane Haggins, Development - a Cultural Studies Reader. London: Balckwell, 2002.

MARCO, Kátia de. A profissionalização dos setores culturais. 2010. Disponível em: <http://www.gestaocultural. org.br/pdf/setoresculturais-KatiadeMarco.pdf $>$. Acesso em: abril de 2012 .

MBAKOGU, Ifeyinwa Annastasia. Is There Really a Relationship Between Culture and Development? Anthropologist, v.6, n.1, p. 37- 43, 2004.

ORTIZ, Renato. Cultura e Desenvolvimento, 2008.

Disponível em: <www.politicasculturaisemrevista.ufba.br>. Acesso em: abril/2012.

PRESSLER, Neusa.: PEDREIRA, Anna Elisa Pedreira. Discurso e Experiência das Agências de Cooperação 
Internacional na Amazônia. In: ANAIS DO XXXIII C.B.C.C. - Caxias do Sul, RS - 2010.

RAO, Vijayendra.; WALTON, Michael (eds.). Culture and Public Action. Stanford: Stanford University Press, 2004.

SACHS, Ignacy. Desenvolvimento: includente, sustentável, sustentado. Rio de Janeiro: Garamond, 2004.

SEN, Amartya. Desenvolvimento como liberdade. São Paulo: Companhia das Letras, 2000.

SHOREMI, M.: "The concept of culture". p.88-105. In: THE SCIENCE of Society: A Sociological Introduction. M. Shoremi, P. Edewor \& O. Olutayo (eds.). Centre for Sandwich Programmes (ESAP), Ogun State University, Ago-Iwoyi, 1999.

SCOTT, James C. Weapons of the Weak: Everyday Forms of Peasant Resistance. Yale U. Press, 1985.

UNESCO. Towards a UNESCO culture and development indicators suite (2009-2010). Link:http://www.unesco.org/ fileadmin/MULTIMEDIA/HQ/CLT/creativity/pdf/culture_and_development_indicators/C+D\%20Indicator\%20 Bibliography.pdf Acesso em abril de 2012.

VEIGA, J. E. Desenvolvimento sustentável: o desafio do século XXI. Rio de Janeiro: Garamond, 2005.

YÚDICE, George. A conveniência da cultura: usos da cultura na era global. Belo Horizonte: UFMG, 2004. 



\section{LIVROS EDUEPB E LATUS}

1. Pluralismo Jurídico: Para além da visão monista - Raíssa de Lima e Melo

2. Mulher, corpo e cuidado - Maria de F. de A. Silveira; e Dulce M. Rosa Gualda

3. Avaliação de serviços: um olhar na qualidade da gestão - (Orgs) Maria José Cariri Benígna; e Maria A. Amado Rivera

4. Farmacêutico na Farmácia - Rosimary S. Cunha Lima; Maria do Carmo Eutálio; e Magnólia de L. S. Targino

5. Representações sociais e saúde - Aliana Fenandes; Maria. do R de Carvalho; e Moisés Domingos Sobrinho

6. EPI Info para iniciantes - (Orgs) Sonia Maria de L. Maciel; e Pedro Henrique de A. e S. Leite

7. Ensino de lingua: do impresso ao virtual - (Orgs) Antonio de Pádua Dias da Silva; Maria de L. L. Almeida; Simone Dália de Gusmão Aranha; e Tereza. N. de Farias Campina

8. A história da mídia regional - C. B de Souza; F. G. de Oliveira; e Gorete M. Sampaio de Freitas

9. Livro de resumo de monografias - Maria Dora Ruiz Temoche

10. Planejamento tributário no campo de incidência do ICMS - Alexandre H. S. Ferreira; e Ana Maria da P. Duarte

11. 1930 - A Revolução que mudou a História do Brasil - (Orgs) João M. L. Santos; Cláudo José L. Rodrigues; Inês Caminha L. Rodrigues; e José Octávio de A. Melo

12. Curso de Direito Constitucional - Lorivaldo da Conceição

13. Fragmentos - Juarez Filgueras de Góis

14. Gênero em questão - (Org) Antonio de Pádua Dias da Silva

15. Jogos eletrônicos - Eliane de M. Silva; Filomena M. G. da S. C Moita; e Robson Pequeno de Souza

16. Nascido do Fogo, Filho da Paz - Ket Jeffson Vasconcelos Leitão

17. Política Tributária e Justiça Social - Alexandre Henrique Salema Ferreira

18. Revista Sócio-Poética - Departamento de Letras da UEPB

19. O Sábio e a Floresta - Moacir Werneck de Castro

20. Universidade e o fazer poético em prosa e poesia - (Orgs) Fabíola Nóbrega; Marcelle V. Carvalho; e Tatiana Fernandes Sant'ana

21. Sustentabilidade - um enfoque sistêmico - (Orgs) Waleska S. Lira; Helio de L. Lira; Maria José dos Santos; e Lincon Eloy de Araújo

22. Bioquímica clínica - uma abordagem geral - Sandra Reis Farias

23. Mortalidade Geral - Epidemologia - Anthonyanny A. Silva Lima; Maria J. Cariri Benigna

24. Estudos Filológicos: Literatura - Cultura - Marinalva Freire da Silva

25. Dicionário de termos relativos a gestão de pessoas - Maria Dora Ruiz Temoche

26. Práticas de Políticas Públicas - (Orgs) Marcelo A. Pereira; Maria da G. A. Pereira; Sandra. M. A de S. Celestino; Sueli Ramos de R. M. Cavalcanti; e Wíliam A. de Lacerda

27. Saúde Humana - (Org) Inácia Sátiro Xavier de França

28. O Segredo de Pergamo - Ket Jeffson Vasconcelos Leitão 
29. A queda do meteorito - Giusone Ferreira Rodrigues

30. Trajetória empreendedora: estudo de casos numa realidade local e global (Org) Vera Lúcia Barreto Motta

31. Identidades de gênero e práticas discursivas - (Org) Antonio de Pádua Dias da Silva

32. O lugar da Educação Física - Maria José de Figueirêdo Gomes

33. O papel político dos fóruns de educação de jovens e adultos - Eduardo Jorge Lopes da Silva

34. Pesquisa histórica - resumo de monografias - (Orgs) Luíra Freire Monteiro; e Flávio Carreiro de Santana

35. Anos de luta - Waldir Porfírio

36. Mulher e violência: histórias do corpo negado - Lígia Pereira dos Santos

37. Agricultura orgânica - José Geraldo R. dos Santos; e Emmanuelly Calina X. R. Santos

38. Sobre o diálogo: introdução a uma leitura filosófica de - Julio Cesar Kestering

39. Novos cenários da Administração - (Org) maria Dora Ruiz Temoche

40. O despertar da cultura - (Org) Marinalva Freire da Silva

41. Manual básico de Radiologia Odontológica - Maria de Fátima Cavalcanti Rodrigues

42. Formas de sociabilidade e instauração da alteridade - Inácia S. Xavier de França; Lorita M. Freitag Paghuca

43. Paremiologia nordestina - Fontes Ibiapina

44. Resistência indígena no Piauí colonial 1718 - 1774 - João Renor F. de Carvalho

45. Planejando o (des)envolvimento local - Roberto Alves de Araújo; e Ana Siqueira de Araújo

46. Deuses em poéticas: estudos de Literatura e Teologia - (Orgs) Salma Farraz; Antonio Magalhães; Eli Brandão; Waldecy Tenório; Douglas Conceição

47. Campina Grande em debate - (Org) Roberto Véras de Oliveira

48. História do Direito e da violência: recortes de uma abordagem interdisciplinar Marcelo Alves Pereira Eufrásio

49. Contos jurídicos: normas de sobredireito da Lei de Introdução ao Código Civil Ket Jeffson Vasconcelos Leitão

50. A Bacia do Rio Gramame: Biodiversidade, uso e conservação - (Orgs) José Etam de Lucena Barbosa; e Takako Watanabe; e R. José da Paz

51. Ser criança - repensando o lugar da criança na educação infantil - (Orgs) Glória M. de Souza Melo; Soraya. M. de A. Brandão; e Marinalva. da Silva Mota

52. Estudos Sociais da Ciência e Tecnologia - (Org) Renato Dagnino

53. De portas abertas para o lazer - (Orgs) Elaine Melo de B. Costa Lemos; Eduardo Ribeiro Dantas; e Cheng Hzin Nery Chão

54. Gênero e práticas culturais - (Orgs) Charliton J. dos Santos Machado; Idalina M. F. Lima Santiago; e Maria L. da Silva Nunes

55. Da resistência ao poder - o (P)MDB na Paraíba (1965 / 1999) - José Otávio de Arruda Mello

56. Políticas públicas e desenvolvimento regional - (Orgs) Carlos. A. Máximo Pimenta; Cecília Pescatore Alves 
57. Histórias vividas e contadas no Bar do Brito - (Orgs) A. C. Barbosa de Souza; Antonio Guedes Rangel Junior; Clara M. Araújo Pinto; e Sonia Maria A. de Oliveira Brito

58. De memória e de identidade - (Orgs) Antonia M. M. da Slva; Francisco Paulo da Silva; Ivanaldo Oliveira dos Santos; e Maria Edileuza da Costa

59. A luz que não se apaga - Rômulo de Araújo Lima

60. Cálculo avançado - (Orgs) Aldo Trajano Louredo; e Alexandro M. de Oliveira; e Osmundo Alves Lima

61. Fisioterapia na gravidez - (Org) Maria do Socorro B. e Silva

62. Educação Universitária - Pedro Bergamo

63. Amora - Fidélia Cassandra

64. Educação em questão - recortando temas e tecendo ideias - (Pedro Lúcio Barboza)

65. Ciço de Luzia - Efigênio Moura

66. Zila Mamede - trajetórias literárias e educativas - Charliton José dos Santos Machado

67. A voz da infância e outras vozes - Calos Azevedo

68. A Educação da Mulher em Lima Barreto - (Jomar Ricardo da Silva)

69. Porta aberta à poesia popular - Almira Araújo Cruz Soares

70. Mulheres representadas na literatura de autoria feminina - Antonio de Pádua Dias da Silva

71. Residências terapêuticas - (Orgs) Maria de Fátima de A. Silveira e Hudson Pires de O. Santos Júnior

72. A nuvem de hoje - Braulio Taveres

73. Tecnologias digitais na educação - (Orgs) Robson Pequeno de Sousa; Filomena M. C. da S. C. Moita; e Ana Beatriz Gomes Carvalho.

74. A representação da sogra na obra de Leandro Gomes de Barros - José Itamar Sales da Silva

75. Viagem aos 80 anos da Revolta de Princesa - Janduí Dantas

76. Cidadania glocal, identidade nordestina - José Marques de Melo

77. Uma nova ciência para um novo senso comum - Marcelo Germano Gomes

78. A feira - o trovador encantado - Maria de Lourdes Nunes Ramalho

79. Nordeste como inventiva simbólica - Geralda Medeiros Nóbrega

80. Era uma vez diferente - Aline Pereira

81. Colecionismo, práticas de campo e representações - Maria Margaret Lopes e Alda Heizer.

82. Ensaios de Antropologia da Política - Elizabeth Christina de Andrade Lima

83. A Bela Acordada - Lígia Pereira dos Santos

84. Eu macharei na tua luta - a vida de ELISABETH TEIXEIRA - (Orgs) Lourdes M. Bandeira; Neide Miele; Rosa M. G. Silveira

85. Apropriação Social da Ciência e da Tecnologia - (Orgs) Maria C. P. I. Hayashi; Cidoval M. de Sousa; e Danilo Rotrberg

86. Midiatização da Ciência - cenários, desafios, possibilidades - (Org) Antonio Fausto Neto

87. Psicologia da Saúde - teoria, intervenção e pesquisa - (Org) Railda Fernandes Alves

88. As periércias de um caçador de ETs - Jorge Dellane da Silva Brito 
89. Becquerel e a descoberta da radioatividade - Roberto de Andrade Martins

90. Mpb de A a Z (2 ediçâo) - Ricardo Anísio

91. ECO - Juarez Filgueras de Góis

92. As três verdades de Deus - Janduí Dantas

93. Sabedoria de cabôco - José Alves Sobrinho

94. Agenda Ambiental - gestão socioambiental - (Org) Antônio Augusto Pereira de Sousa; Djane de Fátima Oliveira; Givanildo Gonçalves de Farias;

e Mercília Tavares Jordão

95. Etnografia e Educação - conceitos e usos - Carmen Lúcia Guimarães de Mattos; e Paula Almeida de Castro

96. Orgulho de ser caririzeiro - Victor Paulo Sampaio

97. Genealogia do Direito à Saúde - Marcone do Ó Catão

98. Antonio Carlos Nóbrega em acordes e textos armoriais - Luís Adriano Mendes Costa

99. Identidades \& sensibilidade - o cinema como espaço de leituras - (Org) Iranilson Buriti 100.Dom José Maria Pires - Uma voz fiel à mudança social - (Org) Sampaio Geraldo Lopes Ribeiro

101.Paisagens Híbridas - Fontes e escrituras da História - (Org) Juciene Ricarte Apolinário

102. Cenários históricos e educativos - Sertão, questão indígena e espaço de saber (Org) Juciene Ricarte Apolinário 


\section{Sobre o livro}

Impressão Gráfica Universitária da UEPB

Formato $15 \times 21 \mathrm{~cm}$

Mancha Gráfica $10 \times 16,5 \mathrm{~cm}$

Tipologias utilizadas Garamond Premier Pro $12,5 \mathrm{pt}$ Franklin Gothic Demi 12,5 pt

Papel Apergaminhado $75 \mathrm{~g} / \mathrm{m}^{2}$ (miolo)

e Cartão Supremo $250 \mathrm{~g} / \mathrm{m}^{2}$ (capa) 
